\title{
PRINCIPALES ASPECTOS DEL SISTEMA PREVISIONAL DE CA- JAS PROVINCIALES NO TRANFERIDAS Y DE LA PROVINCIA DE CORRIENTES
}

Sergio Leandro Claps ${ }^{1}$

\section{Introducción}

Desde los primeros tiempos de la convivencia social se ha comprobado la absoluta necesidad de auxiliar a los miembros más débiles de la sociedad. Es así, como nacen instituciones, imperfectas en un principio, pero que van evolucionando posteriormente hasta llegar al sistema más apropiado que es el constituido por la Seguridad Social.

La seguridad social no debe confundirse con la previsión social, es una relación de género - especie. La primera tiende a la protección de las contingencias sociales en su conjunto, que provocan en los individuos en particular y en general en la sociedad, necesidades económicas generadas por disminución o pérdida de ingresos habituales o por la generación de gastos adicionales.

Todo esto se da como parte de lo que se denomina una sociedad colectiva (es decir aquella que tienen los individuos como integrantes de una sociedad organizada), formando parte de las satisfacciones indelegables que debe realizar el Estado como tal.

Estas contingencias se clasifican en:

a) Origen patológico: salud, riesgo de trabajo;

b) Origen biológico: maternidad, vejez, muerte;

c) Origen económico y social: desempleo, cargas de familia, vivienda.

Se define a la seguridad social:

${ }^{1}$ Profesor Adjunto de la Cátedra “B” de Derecho Civil, segundo curso en la Facultad de Derecho y Ciencias Sociales y Políticas, UNNE. 
Como el conjunto de normas y de principios orientadores ${ }^{2}$ y de medios, instrumentos y mecanismos tendientes a implementar la cobertura eficaz de las contingencias sociales que puedan afectar al ser humano y a su grupo familiar en sus necesidades vitales y en su dignidad intrínseca e inherente a ellas.

El sistema previsional constituye uno de los sub-sistema de la seguridad social destinado a cubrir las contingencias de vejez, invalidez y muerte. Es decir ofrecer ciertas garantías, mediante prestaciones de substitución en caso de una pérdida de ingresos debida a una incapacidad de carácter temporal o permanente (enfermedad, accidente, invalidez o edad), a la pérdida del empleo o la muerte, así como beneficios compensatorios para hacer frente en mejores condiciones que una persona requiere para vivir dignamente.

Las contingencias que protege la previsión social -vejez, invalidez, muerte- ameritan su estudio, toda vez que es una preocupación hoy globalizada el contar con un sistema previsional equitativo y sustentable, con variantes utilizadas que van desde el más tradicional régimen de reparto, hasta el otro extremoimplementado en el país por 10 años a partir de 1994, que es el de capitalización

${ }^{2}$ a) Principio de imprescritibilidad e irrenunciabilidad: este principio es medular en la seguridad social, regulado constitucionalmente en párrafo $3^{\circ}$ del art. 14 bis de la constitución nacional, con carácter de integral e irrenunciable a cargo del estado, son normas de "orden público” y por lo tanto irrenunciables. Sería nulo cualquier acuerdo de partes, que tengo por objeto modificar o desconocer estos derechos consagrados constitucionalmente; b) principio de legalidad y razonabilidad: hay una seguridad jurídica que brinda la ley, principio de legalidad, al delimitar lo que está permitido de lo prohibido, no dejando lugar a conductas arbitrarias para imponer procedimientos o reglamentar leyes que desvirtúen su esencia, principio de razonabilidad. El poder ejecutivo, tiene entre sus atribuciones la de conceder jubilaciones o pensiones, conforme las leyes, siendo asimismo el encargado de dictar las instrucciones y reglamentaciones necesarias para la ejecución de las leyes, cuando siempre de no alterar su espíritu; c) universalidad: debe extenderse a todas las personas, sin distinción de ninguna especie; d) integralidad: debe amparar todas las contingencias; e) igualdad: debe proteger y otorgar iguales prestaciones en iguales circunstancias; f) solidaridad: la ética social impone a los hombres una subordinación del bien individual con el bien común. Así los aportes son una contribución impuesta por razones de solidaridad; g) progresividad: las instituciones fueron creadas para evolucionar constantemente, de acuerdo al contexto social. Su involución, conduce inexorablemente a su extinción; h) naturaleza alimentaria: la seguridad social cubre contingencias donde se debaten riesgos de subsistencia, es decir tutela individuos no aptos laboralmente (acreedores sociales). 
o de administración de los fondos por privados, pasando por otros sistemas mixtos. Pero todos, absolutamente todos los sistema, deben estar bajo la órbita y atención del estudio académico; en la preocupación de profesionales de ciencias jurídicas y de las administraciones públicas para encontrar aquel sistema que proteja el derecho a una vejez digna, luego de haber completado los años de vida laboral activa.

El sistema previsional en nuestro país presenta actualmente la siguiente situación:

a) Multiplicidad de cajas y sistemas compatibles con su estructura federal (más de 125); ${ }^{3}$

b) Diversidad de legislaciones;

c) Atomización de las políticas de acuerdo a los distintos regímenes y sus ámbitos;

d) Cajas provinciales con altos desequilibrios económicos-financieros;

e) Uso arbitrario y discrecional de los fondos del Sistema Previsional;

f) Aspectos demográficos, y económicos sociales propios del sistema que contribuyen a su desfinanciamiento;

${ }^{3}$ a) Régimen nacional: lo que se denominaba SIJP - que era un régimen mixto, coexistencia de un sistema público- de reparto asistido -y las administradoras de fondos de jubilaciones y pensiones (AFJP) - modificado por Ley 26245, se elimina el régimen de capitalización y se pasa a un sistema único: sistema integrado previsional argentino -SIPA-, bajo un sistema de reparto asistido, y están comprendidos dentro de este sistema :trabajadores de la actividad privada, autónomos, trabajadores rurales, amas de casa y empleados públicos nacionales y de provincias transferidas.; b) trece (13) cajas o institutos de previsión social provinciales no transferidos a la nación (Buenos Aires, Córdoba, Santa Fe, Entre Ríos, Corrientes, Chaco, Misiones, Formosa, La Pampa, Neuquén, Chubut, Santa Cruz, Tierra del Fuego). Regímenes públicos, solidarios de reparto (en poder de los estados provinciales), están comprendidos dentro de este sistema empleados públicos provinciales, organismos provinciales descentralizados; empresas de estados provinciales; c) veintisiete (27) cajas municipales (Entre Ríos, Santa Fe, Neuquén). Regímenes públicos, solidarios de reparto (en poder de los estados municipales). Están comprendidos dentro de este sistema empleados públicos municipales; d) setenta y siete (77) cajas de previsión para profesionales. Sistemas mixtos (base solidaria con capitalización). Están comprendidos dentro de este sistema solamente profesionales; e) cuatro (4) cajas de previsión para empleados de bancos provinciales. Base solidaria de reparto; f) regímenes especiales para actividades específicas -base solidaria de reparto-, están comprendidos dentro de este sistema personal militar y actividades específicas con cajas complementarias. 
g) Carencias en la información contenida en los distintos regímenes;

h) Falta de cruzamiento de datos entre las distintas cajas lo que facilita notoriamente el fraude previsional;

i) Insuficiencia de un marco legal adecuado que solucione los conflictos generados en la interrelación de los distintos regímenes previsionales nacional, provinciales, municipales y profesionales-;

j) Y lo más grave falta de política de Estado en materia previsional.

\section{Evolución y análisis de las cajas provinciales}

El sistema jubilatorio en nuestro país se organizó sobre la base de dos sistemas superpuestos. Por una lado, las cajas nacionales de previsión social que agruparon a sus afiliados por la actividad que estos desarrollaban, con prescindencia de la jurisdicción territorial donde se prestaban esos servicios.

Paralelamente, las provincias fueron creando sus propios regímenes jubilatorios, en protección de los empleados públicos provinciales, empleados de las municipalidades de cada provincia, docentes provinciales, jueces, y la policía provincial.

En un principio, los servicios prestados en una caja determinada, solo eran computables como antigüedad dentro del mismo régimen al que pertenecían; pero rápidamente y, sobre todo como consecuencia de las crecientes migraciones laborales, se hizo imprescindible la aparición de un sistema de validación recíproca de los períodos aportados a los diferentes regímenes.

En año 1946 se crea el Sistema de Reciprocidad Jubilatoria, mediante el dictado del Decreto-Ley 9316, permitió interrelacionar los servicios prestados ante cualquiera de las cajas nacionales, para integrar antigüedad a los fines jubilatorios; de modo tal que cada una de ellas debía considerar a los servicios prestados ante las demás, como si hubieran sido cumplidos ante su propio régimen.

Se pasó a un sistema de reparto mediante el cual todos los recursos que ingresaban en concepto de aportes y contribuciones, eran aplicados de inmediato al pago de los beneficios, dentro de un esquema que suponía el cumplimiento de una ecuación matemática entre activos contribuyentes al sistema y pasivos titulares de los beneficios, que por lo menos debía ser de cuatro o cinco 
aportantes para cada beneficiario, a fin de poder mantener la viabilidad de este método de reparto.

Existía un único organismo pagador que afrontaba el pago de las prestaciones con los aportes ingresados por el beneficiario y con los fondos transferidos desde los otros organismos.

Incluyó normas sobre la caja que debía hacerse cargo del otorgamiento de la prestación cuando el titular tenía servicios en dos o más de ellas (caja otorgante), la exigencia de un beneficio único pagado por la caja otorgante, quien recibía la transferencia de aportes de las demás en las que el beneficiario había certificado servicios, la compatibilidad entre el cobro de la jubilación y la continuidad o la vuelta al trabajo, etc.

Hasta el año 1994, la totalidad de las provincias argentinas se habían reservado sus propios regímenes previsionales de acuerdo con las facultades conferidas por el Artículo 125 de la Constitución Nacional.

Como consecuencia de la reforma del Sistema Nacional de Previsión Social y el consiguiente cambio en las relaciones financieras entre la Nación y las provincias. En agosto de 1992 se había firmado el “Acuerdo entre el Gobierno Nacional y los Gobiernos Provinciales” (Pacto Fiscal I), que establecía la cesión del 15\% de la masa coparticipable al financiamiento del sistema previsional nacional. Un año más tarde, la discusión de la prórroga de ese acuerdo derivó en la firma del "Pacto Federal para el Empleo, la Producción y el Crecimiento" (Pacto Fiscal II), en agosto de 1993, que incluyó el compromiso de la Nación de aceptar la transferencia de las cajas de jubilaciones provinciales al Sistema Nacional de Previsión Social.

Se incorporaron al SIJP las cajas de las provincias de Catamarca, Santiago del Estero, Salta, Mendoza, San Juan, La Rioja, San Luís, Jujuy, Tucumán y Río Negro, en cuyo caso el gobierno nacional ha tomado a su cargo el pago de las prestaciones ya en vigencia, y el acuerdo de las que corresponda en adelante, pero sobre la base de la Ley 24241.

Lógicamente, a partir de la vigencia de los convenios, todo el personal de la Administración Pública de dichas provincias, incluidos sus municipios, se convirtió en afiliado al SIJP, ingresando sus aportes y contribuciones al sistema nacional.

En lo relativo a las provincias no transferidas al Sistema Integrado de Jubilaciones y Pensiones, por ahora subsiste el Sistema de Reciprocidad Jubilatoria del Decreto-Ley 9316/1946 que vincula a la ANSeS como órgano representativo del Régimen Previsional Público con las cajas provinciales suscriptoras de ese 
convenio. Entre ellas y la ANSeS se aplica el sistema de caja otorgante, reglado en el art. 168, Ley 24241, que da nuevo texto a los arts. 80 y 81, Ley 18037.

Dado que no todas las provincias transfirieron sus Cajas de Jubilaciones, y ante la cesión de recursos coparticipables para financiar el sistema previsional y la transferencias de las cajas del grupo de provincias que no lo efectuaron, derivó en reclamos de estas provincias que entendieron estaban siendo discriminada al ser utilizados los recursos de ellas cedidos para financiar las cajas de las restantes provincias.

En consecuencia, en Diciembre de 1999, la Nación y los gobernadores suscribieron el "Compromiso Federal”, ratificado luego por la Leyes 25235 y 25400 que incorporó, en su Cláusula $12^{\circ}$ que:

El Estado Nacional financiará con recursos provenientes de Rentas Generales los déficit globales de los sistemas provisionales provinciales no transferidos hasta la fecha del presente convenio en función de los regímenes actualmente vigentes; como los de aquellos sistemas que arrojen déficit provisional originados en forma individual (personal civil, docente, policial, etc.) y las provincias, en contrapartida, deben armonizar sus legislaciones con las pautas de la legislación nacional en la materia. Sobre el gasto en jubilaciones y pensiones, influyen diversas cuestiones. Las más importantes, que explican los resultados financieros y algunas otras cuestiones relativas a la equidad, son las identificadas con: a) edad para jubilarse; b) años de servicios con aporte; c) determinación del haber inicial; $y$ d) movilidad del haber. Las dos primeras tienen que ver con las condiciones de acceso al beneficio y las restantes, con la cuantía del haber. Todas ellas impactan sobre el resultado financiero del sistema.

A partir de este acuerdo se abrió una nueva instancia para la financiación del déficit previsional provincial. No obstante, el régimen instituido por esta ley, para financiar "supuestamente” el déficit previsional de las cajas provinciales no transferidas, no se transformó en la solución esperada, debido a que en la práctica opera como un sistema arbitrario y discrecional que depende exclusivamente del ANSeS, que determina a quien se financia y a quién no. Basta con traer a colación el caso de la provincia de Corrientes que hasta el año 2009, y luego de diez años de vigencia de la Ley 25235, de haber pasado por tres 
auditorías realizadas por el Área de Análisis Económico de Regímenes Provinciales de la ANSES que determinaron de manera fehaciente el déficit de la caja de Previsión Social de la provincia de Corrientes, no se había recibido suma alguna por dicho concepto, mientras que otras cajas previsionales provinciales -Chaco, Buenos Aires, Córdoba, La Pampa, Entre Ríos, Santa Fe, etc.-, si lo habían recibido (sin haber armonizado sus legislaciones), lo que revela el manejo discrecional de los fondos previsionales por parte de la ANSeS,

\section{Crisis de los regímenes previsionales provinciales}

La falta de cumplimiento de la Transferencia de los aportes y contribuciones, ${ }^{4}$ ha sido una de las principales causas del desfinanciamiento de las cajas previsionales. La realidad indica que fue la caja otorgante la que se hizo cargo del pago total del beneficio.

Justamente este marcado incumplimiento de las transferencias de aportes, ha llevado a que muchas instituciones se vieran marcadamente afectadas en sus equilibrios económicos-financieros.

Las entidades más perjudicadas han sido las cajas o institutos provinciales, por el juego de varios factores:

${ }^{4}$ El Decreto Ley 9316/46 en su art. $8^{\circ}$ establecía que la caja otorgante del beneficio recibía de las otras cajas certificantes, la transferencia de los aportes que el afiliado había realizado oportunamente a cada una de ellas, capitalizado a la tasa del $4 \%$ anual. Luego el fenómeno inflacionario irá haciendo perder sentido a estas transferencias, que dejan de hecho de efectuarse hasta que el art. 81 de la Ley 18037, las suprime, incluso convalidando las no efectuadas hasta ese momento. Finalmente, con la sanción de la Ley 24241, reglamentado por el decreto 78/94, dio un nuevo texto al art. 80 y 81 de la Ley 18037, en el art 168, restableciendo el mecanismo de la transferencia de aportes a la caja que resulte otorgante de la prestación, que será aquella en la cual el afiliado registre la mayor cantidad de años con aportes y, en caso de igualdad entre dos o más, el afiliado podrá optar por una de ellas. La transferencia debía efectuarse en moneda de curso legal en forma mensual y de acuerdo al procedimiento que determinara la secretaría de seguridad social -a la que facultaba expresamente para ello y para suscribir los convenios que fueran necesarios para su instrumentación-, nunca se avanzó al respecto. El mayor obstáculo para ello, radicaba en la dificultad que se planteaba en la efectivización de las transferencias, que ya había acusado el régimen del Decreto-Ley 9316/46, que en la práctica había resultado útil a los efectos del reconocimiento de la antigüedad del servicio prestado, pero que distaba de mostrar igual utilidad en cuanto a la determinación del haber, sobre todo por efecto de las distorsiones ocasionadas por los ciclos inflacionarios. Lo que motivó la suspensión en los hechos de todas las transferencias. 
a) Históricamente las cajas provinciales han pagado mejores haberes;

b) Sus normativas establecieron cómputos de privilegios con escasas exigencias para resultar cajas otorgantes.

Todo esto trajo como consecuencia que los afiliados sistemáticamente optaran por los institutos provinciales, con las consecuencias económicas que significa para estos tengan que pagar la totalidad de los haberes sin recibir los aportes realizados.

Esto genero indefectiblemente que los regímenes provinciales, incurrieran en situaciones deficitarias al tener que pagar prestaciones que incluían servicios prestados ante otros organismos que directamente no les transfirieron los aportes que ellos recibieron, o bien que tales transferencias resultaron claramente insuficientes para afrontar la carga que supone el pago vitalicio de la prestación.

Por lo que, en la actualidad la mayoría, de las cajas previsionales provinciales, optaron por tomar en cuenta los servicios prestados en otras cajas solamente a los fines de la antigüedad, pero no respecto de la determinación del haber, lo que genera un enorme perjuicio para el beneficiario, que ve disminuido significativamente su haber previsional. Lo que genera una enorme litigiosidad y sin lugar a dudas, numerosas sentencias favorables a las pretensiones de los solicitantes. Lo que va a representar una enorme deuda de las cajas previsionales provinciales para con sus beneficiarios.

A este estado de situación debemos agregarle las principales variables que condicionan el funcionamiento del sistema previsional:

a) Las variables demográficas que son las que influyen directamente sobre la cantidad y cambios en el número de activos y pasivos en una sociedad y definen los límites estructurales de la «Tasa de Sostenimiento» del sistema previsional, es decir, la relación entre aportantes y beneficiarios.

La fuente de recursos genuinos del sistema, se encuentra en serios problemas, si se considera que con 5.585 .000 pasivos y 7.300.000 cotizantes regulares (datos de recaudación de la AFIP) por cada jubilado hay 1,3 trabajadores que contribuyen, contando asalariados, y monotributistas (datos demográficos estimados por el Centro Latinoamericano y caribeño de demografía -Celade). Las cajas previsionales provinciales se encuentran en la misma situación, no hay más de 2,5 aportantes por cada jubilado.

En el mismo sentido funciona el incremento que ha venido teniendo la esperanza de vida al nacer, repercutiendo en una mayor permanencia en el grupo de pasivos una vez logrado el beneficio previsional. 
El avance de la expectativa de vida, que prolonga el periodo en que el Estado se obliga a pagar. Según los informes de la CEPAL, los varones que llegaron al mundo en 1970 tenían entonces una esperanza de vida de 63 años pero al cumplir sus 25 años la expectativa se elevó a 68 años y al cumplir 60, la esperanza subirá a 73 años. Para quienes están naciendo este año, la expectativa es de 88 años para la mujer y de 82 para el hombre.

Las variables demográficas son de carácter estructural y se muestran como irreversibles, solo podrían realizarse cambios en el propio sistema jubilatorio tendientes a incrementar el número potencial de aportantes, disminuir relativamente el de pasivos o aumentar el porcentaje que se retiene en concepto de aportes y contribuciones o bien establecer financiamiento externo.

b) Dentro de un segundo grupo de variables relevante para analizar la crisis del sistema previsional es el vinculado a factores de índole económico social, que inciden significativamente en el funcionamiento del sistema previsional:

- La caída del salario;

- El aumento del empleo informal y de las ocupaciones precarias;

- El desempleo;

- La inflación;

- La evasión;

- El pago de ítemes en negro.

Son variables que minaron drásticamente las posibilidades de financiamiento de los sistemas que como, el previsional o el de obras sociales obtienen sus recursos básicamente de las cotizaciones que realizan trabajadores y empleadores en base a la nómina salarial.

c) Y por último, hay factores internos, propios del régimen jubilatorio:

1. Ante todo, la ausencia de una política social a largo plazo que fuera monitoreando el sistema previsional y aplicando los correctivos necesarios para su continuidad, previa definición clara de sus objetivos;

2. El proceso de «maduración» propio de todo sistema previsional que remite al aumento progresivo y sistemático del número de beneficiarios a través del tiempo. Este proceso hace que inevitablemente se invierta progresivamente la ecuación que en los orígenes del sistema 
implicó gran cantidad de aportantes y pocos beneficiarios, complicando las finanzas del régimen jubilatorio.

3. La existencia de políticas que permitieron el fácil acceso a los beneficios jubilatorios -Jubilaciones de Privilegios-. En los que con menores requisitos de edad y servicios respecto del régimen general, otorgaban haberes cuya determinación no se efectuaba en función de un promedio de remuneraciones, sino considerando el sueldo percibido al momento del cese; a lo que se sumaba que la movilidad (actualización) de este haber se realizaba sobre la base del incremento del sueldo del cargo que se había desempeñado.

4. El problema de los regímenes especiales -policías, docentes, judiciales, bancarios, etc.-, que inciden financieramente de manera significativa y negativamente sobre el sistema general.

5. Ausencia de efectivos controles sobre la «evasión previsional», lo que permitió su rápido incremento.

6. Políticas de reducción o supresión de las contribuciones patronales, lo que implicaba una importante disminución en los ingresos naturales del sistema.

7. Deficiente administración del sistema, lo que se traducía en: considerables atrasos en la tramitación de los beneficios, lo que implicaba que al momento del pago- debían abonarse importantes sumas en concepto de retroactivos.

8. El proceso inflacionario sufrido afectó sensiblemente el equilibrio ingresos/egresos del sistema previsional. Estas y otras razones, se manifestaban en una disminución cada vez más marcada del haber de las prestaciones que el sistema abonaba a sus beneficiarios.

De no mediar cambios profundos en el régimen previsional, indefectiblemente esto conducirá a la falta de sustentabilidad del sistema en el tiempo, principalmente en lo que respecta a los regímenes previsionales provinciales. Lo que inexorablemente va conducir a que todas las cajas provinciales y municipales se vean obligadas a transferir sus regímenes previsionales definitivamente a la Nación, ${ }^{5}$ unificando el sistema previsional en nuestro país y como

${ }^{5}$ Que fue claramente la intención de la Ley 24241 al modificar este sistema a través de su art. 168 y que no por casualidad está ubicado metodológicamente en el libro ii de disposiciones complementarias y transitorias; y ello así, puesto que en la inteligencia del SIJP, en breve plazo 
consecuencia, estableciendo un único régimen legal aplicable. Lo que repercutiría, sin lugar a dudas, negativamente en los gobiernos provinciales o municipales, que tendrían que soportar el alto costo social.

\section{Sistema previsional de la provincia de Corrientes}

El régimen previsional de la provincia de Corrientes, es un sistema de reparto puro que está financiado principalmente por los aportes y las contribuciones de los afiliados y empleadores, respectivamente.

El Instituto de Previsión Social de la Provincia de Corrientes (IPS) se rige por Ley No 4917 (texto ordenado según Decreto-Ley N 22/00, No 167/01, N ${ }^{\circ}$ 158) y el mismo funciona como ente descentralizado del Poder Ejecutivo, con personalidad jurídica y autarquía financiera y tiene por objeto el cumplimiento de los fines de previsión y seguridad social perseguidos por el Estado mediante el otorgamiento de jubilaciones, pensiones y toda clase de prestaciones instituida por el presente o por leyes posteriores.

\section{Beneficios}

En cuanto a los beneficios o prestaciones jubilatorias contempladas por la ley actualmente vigente son las siguientes:

1) Jubilación ordinaria (contingencia de vejez):

Requisitos: Haber cumplido 60 años para las mujeres y 65 para los hombres; y acreditar 30 años de servicios con aportes, continuos o discontinuos, dentro del sistema de reciprocidad jubilatoria. (Art. 41).-

2) Jubilación por invalidez:

Requisitos: Corresponderá jubilación por invalidez al afiliado en actividad bajo el régimen de la presente ley que se incapacite física o intelectualmente en forma total por cualquier causa. Se presume que la incapacidad es total cuando la invalidez produzca en su capacidad laborativa una disminución del sesenta y seis por ciento (66\%) o más. (Art. 45 de la Ley 4917).

la totalidad de las cajas provinciales y municipales del país iban a estar integradas al régimen de la Ley 24241, razón por la cual el mecanismo de caja otorgante era solamente un arbitrio transitorio utilizable mientras esa total unificación de regímenes se concretara. 
3) Pensión (contingencia de muerte):

Requisitos: En caso de muerte del jubilado, del beneficiario de jubilación por invalidez, del afiliado en actividad, del afiliado que hubiese cumplido efectivamente los treinta (30) años de servicios y que no alcanzare las edades mínimas requeridas por la ley vigente, o del afiliado que, cualquiera fuere su tiempo de servicios, hubiere cesado en la actividad hasta un (1) año antes de la fecha del fallecimiento por circunstancias que no enerven sus derechos jubilatorios, tendrán derecho a pensión (art. 56).

Respecto de esta cuestión me parece importante resaltar dos aspectos, por un lado, que los beneficios contemplados actualmente en la ley previsional provincial $N^{\circ} 4917 / 95$, protegen y cubren adecuadamente todas las contingencias previstas por la Previsión Social (Vejez, invalidez y muerte); y por otro lado, que el sistema actual de la provincia no contempla regímenes especiales o de privilegios (Legisladores, judiciales, Docentes, Autoridades superiores, etc.), que son justamente los que repercuten negativamente sobre los recursos de la institución, siendo la única excepción a esta regla, el régimen de Retiros Policiales (Ley $\mathrm{N}^{0} 3439$ ), que justamente es la que mayor impacto tiene en el déficit del sistema previsional de la provincia.

Por lo que, entiendo que en esta cuestión no debería introducirse modificación alguna, si en todo caso, modificarse el sistema de retiros policiales a los fines de reducir las marcadas diferencias que actualmente existen con relación al régimen general (principalmente en lo que tiene que ver con la edad y años de servicios con aportes necesarios para acceder al beneficio; y con la determinación del haber), si justamente lo que se busca es contar con un sistema previsional sustentable en el tiempo.

\section{Determinación del haber}

El art. 35 de la Ley 4917/95 (texto ordenado según Decreto-Ley No 22/00, № 167/01), respecto de la determinación del haber, dispone que:

El haber de la Jubilación Ordinaria o por invalidez, será equivalente al ochenta y dos por ciento (82\%) del promedio de las remuneraciones con aportes, efectivamente percibidas por el agente en cualquiera de los entes comprendidos en el art. $20^{\circ}$, correspondiente a los ciento veinte (120) meses anteriores al cese Provincial. 
Dicha base se incrementara en doce (12) meses por cada año calendario, a partir del $1^{\circ}$ de enero de 2002, hasta doscientos cuarenta (240) o la totalidad de los servicios computados a esta Caja, si no alcanzaran esa antigüedad pero fueran suficientes para obtener el beneficio dentro de este régimen. No se tendrán en cuenta, para el cálculo del haber, remuneraciones percibidas en servicios simultáneos, en cuyo caso y por el periodo en que hubieren existido, se considerara únicamente -para cada mes- la mejor remuneración con aportes, efectivamente percibida en cualquiera de los entes comprendidos en el art. 20.

Respecto de este tema me parece ilustrativo traer a colación lo resuelto reiteradamente por los tribunales locales (Exma. Cámara de Apelaciones en lo Laboral de la Pcia. de Corrientes, ratificado por el Superior Tribunal de Justicia de la Pcia. de Corrientes) ${ }^{6}$ respecto de esta cuestión, donde se plantea la inconstitucionalidad de los Decretos-Leyes 22/00 y 167/01, modificatorio del art. 35 de la Ley 4917/95, por ser violatorios de los derechos y garantías de la Constitución Nacional.

La Cámara sostiene de manera reiterada en sus considerandos que:

no caben dudas que las reformas introducidas por los decretos leyes 22/00 y 167/01 a los arts. 35 y 67 de la Ley $N^{o}$ 4917/95, desconocen la supremacía de la Constitución Nacional, reemplazando el "Cargo-base" y "Cargos Acumulados" por el "haber Inicial", recurriendo a un promedio de los últimos ciento veinte meses anteriores al cese, afectándose la movilidad. (...) las normas que modificaron el régimen de determinación del haber previsional chocan

\footnotetext{
${ }^{6}$ Fallos del superior tribunal de justicia de la pcia. de Corrientes: "Codazzi Liliana Gladis c/ instituto de previsión social Ctes. y estado de la provincia de Ctes. $\mathrm{s} /$ amparo" expediente $\mathrm{n}^{\circ}$ edl - 699/10; "centro de jubilados y pensionados de la Pcia. de Ctes. c/estado de la Pcia. de corrientes e instituto de Previsión social s/Acción contenciosa administrativa” expediente n ${ }^{\circ}$ std 241/8; "Tiengo Graciela del Carmen c/ estado de la Pcia. de corrientes e instituto de Previsión social de la Pcia. de corrientes s/ amparo", expte. n 207; "Encinas Alfredo Ramon c/ estado de la provincia de Ctes. e instituto de previsión Ctes. s/ amparo” expediente $n^{0}$ edl - 418/9; “Aquino de Pasi Nilda Noemi c/estado de la pcia. de Corrientes e instituto de previsión social s/recurso facultativo" expediente n ${ }^{\circ}$ std 289/8; "Franco Herminia Severa c/ instituto de previsión social de la provincia de Corrientes s/ amparo” expediente $n^{\circ}$ cax 455/11.
} 
frontalmente con las garantías constitucionales contenidas en los arts. 14 bis y 17 de la constitución Nacional, vulnerando de manera ostensible los derechos de la Seguridad Social al desconocer la necesaria proporcionalidad que debe existir entre el haber de pasividad y el de actividad, en razón de la naturaleza sustitutiva que cabe reconocer al primero respecto al segundo. Así el nuevo régimen legal impuesto por la intervención para la determinación del haber previsional ha degradado sustancialmente la prestación previsional del amparista, razones que me llevan a confirmar que tales normas no superan el examen de constitucionalidad. (...) Es reiterada la doctrina de la Corte -según el cual - el principio básico que sustenta el sistema previsional es la necesaria proporcionalidad que debe existir entre el haber de pasividad y el de actividad, entendiendo dicha relación como parámetro razonable para conjugar la naturaleza del haber previsional. (Doctrina de Fallos: 289:430 y sus citas: 292:447).

En consecuencia la Cámara resuelve:

Decretar la inconstitucionalidad de los Decretos-Leyes $N^{o} 22 / 00$ y 167/01, disponiéndose que la liquidación de la jubilación se adecue a lo normado por los arts. 35, 65 y 67 de la Ley 4917/95 vigente antes de la reforma introducida por los citados Decretos.

Esto quiere decir, que a los fines de la determinación del haber, la Cámara y el Superior Tribunal de nuestra provincia, toman en cuenta: "el cargo mejor remunerado desempeñado por el agente en cualquier momento de su vida laboral (...) durante un mínimo de cuarenta y ocho meses” (art. 35, Ley 4917/95).

Realmente, cuesta encontrar argumentos que convaliden la interpretación de la jurisprudencia local, cuando la doctrina y la jurisprudencia de la Corte Suprema avalan el criterio (que compartimos) que la debida proporcionalidad se garantiza cuando la determinación del haber se efectúa sobre la base de los aportes realizados y de los haberes percibidos por el trabajador durante su vida laboral. Asimismo, entiéndase que "debida proporcionalidad" entre el haber en actividad y el de pasividad, no significa "igual”, pues de lo contrario, la Corte Suprema y la Cámara de la Seguridad Social en sus fallos hubiese utilizado ese término. 
En tal sentido, el texto del art. 35 de la Ley 4917/95 (modificado por el Decreto Ley 22/00 y 167/01), cuando dispone que:

el haber de la Jubilación Ordinaria o por invalidez, será equivalente al ochenta y dos por ciento (82\%) del promedio de las remuneraciones con aportes, efectivamente percibidas por el agente..., correspondiente a los ciento veinte (120) meses anteriores al cese Provincial.

De ninguna manera resulta desproporcionado y menos aun puede ser tildado de inconstitucional, si no que por el contrario se ajusta a los criterios de la doctrina y jurisprudencia dominante en nuestro país.

Ahora bien, si los Tribunales locales consideraron que la determinación del haber dispuesta por el citado art. 35 de la Ley 4917/95, resultaba excesiva, podían haber dictado una sentencia, “con cierta razonabilidad”, tomando como parámetro lo dispuesto por la Ley Nacional No 24.241, es decir sobre la base de "los últimos diez años de servicios con aportes anteriores al cese", pero de ninguna manera ordenar la determinación del haber en base al cargo mejor remunerado durante un mínimo de 48 meses, porque ahí si se vulnero el principio de la razonable proporcionalidad, además de poner en serio riesgo los recursos de la institución. Esta interpretación de la Jurisprudencia local que retoma un artículo derogado, para fijar un parámetro excesivo, parece haber sido hecha para favorecer a ciertos sectores (Legisladores, Jueces, Autoridades Superiores del Poder Ejecutivo, Miembros de junta, etc.), resulta inadmisible dado que revela un desinterés absoluto por la sustentabilidad del sistema.

Distinta es la situación de la falta de reconocimiento legal (art. 35 de la Ley 4917/95 (modificado por el Decreto Ley 22/00 y 167/01) de los cargos simultáneos a los fines de la determinación del haber, porque en este caso si se estaría afectando un derecho de propiedad reconocido expresamente por el art. 17 de nuestra Constitución Nacional, además de incumplir con el sistema de reciprocidad jubilatoria impuesta por el Decreto-Ley 9316/46. Recordemos que esta norma tiene el carácter de Estatuto Federal al cual deben subordinarse todas las disposiciones provinciales, y que la incorporación de las provincias al referido régimen de reciprocidad las obliga a adecuar su legislación local a los imperativos del Estatuto, en los casos de situaciones integradas por elementos supra o extraprovinciales.

Por eso, entiendo que una futura reforma al Régimen actualmente vigente respecto de este tema debe hacerse sobre la base de reconocer que el haber 
previsional debe guardar una razonable proporcionalidad con los aportes realizados y con los haberes percibidos en actividad. Es decir que, el haber previsional debe estar estrechamente vinculado con la historia previsional del trabajador, y no con lo percibido por ese trabajador durante su último periodo de trabajo y menos aun, tomar como base el cargo mejor remunerado, puesto que de hacerlo, repercutiría negativamente sobre el patrimonio de las Cajas, al tener que pagar en concepto de beneficios, sumas que no guardan una justa proporción con los aportes realizados y con lo percibido por ese trabajador durante su vida laboral (jubilaciones de Privilegios).Es por esto que sostenemos que, la determinación debe hacerse sobre la base de los últimos o mejores diez (10) años de servicios con aportes, y contemplando los cargos simultáneos prestados por el trabajador, de modo que el haber resultante refleje de manera más adecuada toda la historia previsional de ese trabajador.

\section{- Haber mínimo:}

Es el que tiene por finalidad el otorgar a todo tipo de beneficiario de la previsión social una prestación cuyo importe le permita atender a su subsistencia -y de su familia en su caso-, aunque solo sea en forma totalmente básica y alimentaría. Se trata de una cobertura solidaria y redistributiva, que se atiende sobre la base de recursos que tienen principalmente origen fiscal y cuyo gestor es el Estado. No es necesario que exista una correlación entre el monto de esa prestación mínima y los aportes que el beneficiario haya realmente ingresado al sistema.

En nuestra provincia se verifica una situación anómala, que no registra antecedente alguno en el derecho comparado, que por lo arbitraria no puedo dejar de comentar brevemente. Por un acto administrativo, se determinó el haber mínimo para los beneficiarios dependientes de la administración central y por otro, se fijó un haber mínimo distinto para los beneficiarios municipales, creándose una suerte de jubilados de primera y otros de segunda. Es evidente que tal norma legal es absolutamente discriminatoria e inconstitucional, puesto que atenta contra el principio de igualdad consagrado expresamente por el art. 16 de la Constitución Nacional. Un principio de estricta justicia y de lógica jurídica impone al Estado la obligación de garantizar a los jubilados, en concepto de haber mínimo, un importe único e igualitario, independientemente de la re- 
partición u organismo del Estado donde se hubiera prestado el servicio y de los aportes efectuados.

Asimismo, de manera reiterada, se sostiene que el haber mínimo de nuestra provincia está por encima del haber mínimo nacional, resaltando la política previsional del gobierno que, según dice le permite ubicarse por encima de la ANSeS.

Si bien es cierto lo expresado respecto de que, el haber mínimo garantizado para la administración central de la Provincia está por encima del monto que abona la Nación por el mismo concepto. Se trata de una información deliberadamente parcial, debido a que omite consignar el impacto que cualquier decisión efectuada por el gobierno nacional sobre el haber mínimo tiene sobre los recursos de la ANSeS y sobre el universo de beneficiarios comprendidos. ${ }^{7}$ Esto es así, por cuanto que, cada vez la Nación incrementa el monto del haber mínimo esto repercute sobre 4.500.000 beneficiarios, lo que representa el 70\% del total de jubilados, como así también, sobre lo que se paga en concepto de jubilaciones (el pago de la mínima representa más del $60 \%$ de lo que se paga en concepto de beneficios). Situación muy distinta al de nuestra provincia donde los beneficiarios comprendidos dentro de la mínima son aproximadamente 10.000 agentes, lo que significa solamente el 35\% del total de los beneficios y menos del $18 \%$ de lo que se abona en concepto de beneficios, ergo, el pago del haber mínimo en nuestra provincia no tiene una incidencia sobre las finanzas del IPS, de la envergadura que sí tiene sobre la ANSeS.

Esta diferencia que surge claramente del párrafo anterior, torna aun más incomprensible la norma legal que estableció una discriminación en el monto del haber mínimo entre empleados provinciales y municipales.

\section{Sistema de reciprocidad}

El artículo 36, del mismo cuerpo normativo (Ley 4917/95) establece que:

\footnotetext{
${ }^{7}$ Sistema nacional: haber mínimo: \$ 2.165; jubilados comprendidos: 4.500.000, lo que representa más del 70\% del total de beneficiarios (5.700.000); el pago de los mínimos representa más del 60\% de lo que se paga en concepto de beneficios. Sistema provincial (corrientes): haber mínimo: en la provincia lo que se paga en concepto de mínimo no alcanza los \$26.000.000, lo representa aproximadamente el 18\% de lo que se paga en concepto de beneficio (\$142.000.000) jubilados comprendidos: aproximadamente 10.000, lo que representa - el $35 \%$ del total de beneficiarios (25.268).
} 
Cuando se computen servicios en otros regímenes comprendidos dentro del sistema de reciprocidad, el Instituto de Previsión Social de la Provincia aplicarán las disposiciones del Artículo 168 de la Ley nacional $N^{\circ}$ 24.241.

En consecuencia, en tales casos será organismo otorgante de la prestación cualquiera de los comprendidos en dicho sistema de reciprocidad en cuyo régimen se acredite haber prestado mayor cantidad de años de servicios con aportes. Si existiese igual cantidad de años de servicios con aportes, el afiliado podrá optar por uno u otro organismo otorgante.

Cuando el Instituto de Previsión Social de la Provincia sea el otorgante del beneficio, deberá requerir la transferencia de aportes, contribuciones y cargos correspondientes a los servicios de otras jurisdicciones que se tomen en cuenta. Hasta tanto el Poder Ejecutivo Nacional reglamente las transferencias previstas en el Artículo 168 de la Ley nacional $N^{\circ} 24.241$, el Instituto deberá tramitar y otorgar los beneficios sin recibir la transferencia previa.

Una vez dictada dicha reglamentación, las demoras en las transferencias no imputables al interesado no impedirán el otorgamiento y liquidación de los beneficios en esta jurisdicción.

En todos los casos el Instituto deberá reclamar la transferencia que corresponda.

Los servicios comprendidos dentro del sistema de reciprocidad serán computados de acuerdo a las normas del régimen al que pertenecen dichos servicios.

Actualmente la provincia se encuentra adherida al régimen de reciprocidad instituido por el Decreto - Ley 9316/46, por lo que se consagra la ficción de reconocer todos los servicios como si pertenecieran al mismo régimen que otorga el beneficio. Asimismo, sigue los lineamientos instituidos por el artículo 168 de la Ley 24241, a los fines de determinar la caja otorgante del beneficio.

Respecto de esta cuestión, en la actualidad, se plantea el problema respecto de la interpretación "imperativa o literal” que se hace del artículo 168 de la Ley 24241, que como vimos con anterioridad, dispone que:

sea organismo otorgante, dentro de los comprendidos en el régimen de reciprocidad, aquel en el que se acredite haber prestado mayor cantidad de años de servicios con aportes, derivando a la opción del afiliado el organismo otorgante en caso de existir cantidades iguales en diversas cajas. 
Es decir que si una persona acredita 20 años en una caja provincial y 15 en otra nacional, será caja otorgante la caja provincial por tener la mayor cantidad de años con aporte.

Ahora bien, no siempre esta cuestión de determinar cuál será la caja otorgante del beneficio se presenta tan sencilla al momento de resolver.

El tema plantea los siguientes interrogantes:

1. ¿Es o no voluntario el uso del régimen de reciprocidad jubilatoria? En principio, no es optativo en virtud de que:

El régimen de reciprocidad adquiere "el carácter de un estatuto federal, al cual deben subordinarse las disposiciones provinciales en mérito de lo prescripto por el artículo 31 de la Constitución. La supremacía del sistema de reciprocidad jubilatoria, cuya dirección incumbe al Estado federal, invalida toda norma provincial que, en contradicción con el Decreto-Ley 9.316/46 y disposiciones complementarias, regule situaciones previsionales (...). La incorporación de la provincia al régimen de la reciprocidad la obliga a adecuar su legislación local a los imperativos del estatuto básico, en los casos de situaciones integradas por elementos supra o extra provinciales, según la terminología de la Corte. (Bidart Campos)

2. En consecuencia, ¿puede el afiliado renunciar a los servicios con aportes que él desee, para la obtención, de un beneficio previsional?

Por ejemplo, si, al cumplir la edad jubilatoria, trabajó 40 años con aportes a la ANSeS. y 25 años con aportes a la Caja de Jubilaciones y Pensiones de la Provincia de Corrientes, puede seleccionar los años que desee para que se le computen para el reconocimiento del derecho al beneficio: en el caso, 5 no simultáneos en el orden nacional (para computar 30 años y con ello, tener derecho al 82\%).

Por supuesto que con ello logrará que la Caja otorgante sea la provincial (computaría 25 provinciales y 5 nacionales), que paga prestaciones mejores que la ANSeS.

La letra fría de la ley no permite la opción. Sin perjuicio de ello, la renuncia a servicios no es un invento: la Ley Nacional 25321 admite la renuncia de servicios autónomos, con la única condición de que el afiliado tenga derecho a un beneficio previsional. Posibilito a los trabajadores autónomos la renuncia de servicios cuando se cumplen los requisitos mínimos, permitiendo el reconocimiento de servicios parciales, sobre todo, cuando tales reconocimientos de 
servicios van a ser llevados a cajas provinciales. Pudiendo reconocer solo el mínimo indispensable para obtener la prestación, dejando de lado otros servicios, que determinarían una caja otorgante diferente.

Ante esta situación, no se estaría creando una suerte de desigualdad (aplicación de la regla de la caja otorgante) respecto de no admitir la renuncia de servicios en relación de dependencia, sean nacionales, provinciales o profesionales.

¿Sería razonable obligar a un profesor universitario y juez al mismo tiempo, a renunciar a su cátedra, porque al transmitir su conocimiento y experiencia, estaría sumando años con aportes a la ANSeS, y en consecuencia, condenándose a una jubilación que no guardará relación con el nivel de vida alcanzado en actividad? Conceptualmente: ¿podría perjudicar a alguien el hecho de trabajar y aportar más?, ¿sería esta interpretación compatible con el principio a la igualdad, con el derecho a trabajar, en fin, con la Constitución? ¿Sugiere la Constitución evitar aportar al sistema, la evasión o la elusión?

Considero que de ninguna manera, se puede castigar al que más trabajó y más aportó. No podemos, axiomáticamente, argüir que "si alguien trabajó de más, y necesita solo de algunos servicios, que se haga cargo de las consecuencias disvaliosas de su mayor esfuerzo". No queremos admitir que sea necesario ocultar el trabajo para no ser preso, en la pasividad, del propio trabajo. Lo que se reclama no son mayores beneficios (privilegios), sino simplemente evitar perjuicios.

Otra situación que puede plantearse es que suele plantearse reiteradamente es la de un trabajador " $A$ " con treinta años con aportes a una caja "Provincial” que paga jubilaciones sobre la base del 82\% móvil, y otro trabajador "B" que aportó treinta años a una caja "Nacional" con haberes que no superan el $60 \%$. Si un trabajador "C" de jornada completa que aportó treinta y dos años a la caja "Provincial” y treinta y tres a la "Nacional”, ¿puede renunciar a computar estos últimos servicios, y jubilarse exclusivamente con los de la caja “A”? Quien trabaja más y aporta más no puede ser acreedor de una jubilación menor a la de quien trabaja y aporta menos. Una interpretación distinta vulneraría el principio constitucional de igualdad.

Los convenios de reciprocidad se celebraron para beneficiar a los trabajadores, y no para perjudicarlos. Es decir no pueden restringir sus derechos, sino solo ampliarlos, tanto por su ya referida razón de ser, cuanto por la consideración de los derechos de la seguridad social como derechos humanos.

En relación con lo dispuesto en el art. 75, inc. 22, “El reconocimiento del principio de progresividad en la satisfacción plena de 
estos derechos destierra definitivamente interpretaciones o medidas que puedan ser consideradas regresivas en la materia (art. 29 de la Convención Americana sobre derechos Humanos)", al decir de la Corte. El principio de no regresividad de los derechos humanos implica que, una vez que se ha alcanzado un grado de protección de un determinado derecho, el Estado debe evitar la disminución de la referida protección. Progresividad significa, además, que el Estado debe realizar los esfuerzos que estén a su alcance, para incrementar aquella protección. Por la no regresividad, un afiliado sigue teniendo la posibilidad de computar servicios aportados solo a una de las cajas en las que cotizó en su vida laboral. ${ }^{8}$

La misma conclusión se desprende razonablemente de la lectura conjunta de las normas previsionales y los arts. 14, 14 bis, 16 de la Constitución Nacional, y similares de la Constitución Provincial.

"La regla de la Caja otorgante no puede entenderse frustratoria de derechos cuando su razón de ser ha sido facilitarlos”. En tal sentido me parece ilustrativo traer a colación el siguiente fallo:

El Tribunal Superior de Justicia de la Provincia de Neuquén ratifico lo resuelto por la Cámara de Apelaciones en lo Civil, Comercial, Laboral y de Minería -Sala I- de la ciudad de Neuquén, mediante la cual se hace lugar a la acción de amparo, ordenando, en consecuencia, a la demandada - I.S.S.N -que dentro del plazo legal otorgue a la Sra. Ríos el beneficio jubilatorio.

La actora -Sara Elena RÍOS- promueve acción de amparo contra el INSTITUTO DE SEGURIDAD SOCIAL DEL NEUQUÉN. Por cuanto que se le denegó el benefició de jubilación ordinaria sobre la base de que, por aplicación del sistema de reciprocidad jubilatorio, el A.N.Se.S. debe ser la caja otorgante por poseer mayor tiempo de aportes -24 años, 4 meses y 14 días de servicios con aportes al I.S.S.N. y 30 años, 5 meses y 25 al A.N.Se.S -.

Respecto de esta cuestión, la Cámara sostuvo que:

La aplicación del régimen de reciprocidad en este caso resulta arbitraria, irrazonable y claramente perjudicial, por lo que declara la

${ }^{8}$ CSJN, “Pecora, Humberto c. provincia de salta”, 02/04/1985, La Ley, 04/09/1985, “Actualización de jurisprudencia”, nro. 402. 
inconstitucionalidad del Art. 168 de la Ley 24.241, por entender de que afecta derechos constitucionales respecto de los beneficios de la seguridad social (Art. 14 bis C.N.), afecta el principio de igualdad (Art. 16) y el de propiedad (art. 17) de la Carta Magna. El sistema de reciprocidad jubilatoria tuvo en miras, como una de sus facultades esenciales, beneficiar a los afiliados al sistema y no a los organismos previsionales. De allí, que toda interpretación deba sustentarse sobre esos principios y en la no abdicación de la provincia a sus facultades legislativas, en respeto a la manda constitucional. ${ }^{9}$

Otras de las cuestiones que plantea el régimen de reciprocidad jubilatoria, ha sido el fracaso del sistema de transferencia de aportes y contribuciones en nuestro país, siendo la caja otorgante la que se tiene que hacer cargo del pago total de los beneficios, con el agravante que significa el pago vitalicio de los mismos.

Entiendo, que una reforma al sistema previsional en materia de cómputo reciproco de servicios prestados ante distintas cajas previsionales, debe darse sobre la base del principio de la Prorrata Tempore, donde cada régimen pague la prorrata del beneficio que a él compete. Con este sistema se solucionarían todas las cuestiones planteadas con anterioridad (determinación de caja otorgante, como asimismo, los enormes problemas financieros que genera el incumplimiento de las transferencias de aportes y contribuciones). El sistema funciona adecuadamente en la reciprocidad internacional y en el régimen de cajas profesionales.

Inclusive permitiría que la caja que otorga prestaciones con escasos requisitos para el acceso y con montos de haberes muy considerables, tenga que afrontar siempre su prorrata de tales prestaciones que no serán abonadas por el resto de los organismos participantes del beneficio. Esta situación, conduciría a las provincias respectivas a modificar su legislación para evitar la carga financiera que ello le supondría. Y asimismo, evitar la especulación sobre caja otorgante.

\section{Movilidad de las prestaciones}

En lo que respecta a la movilidad el Art. 67 establece que:

${ }^{9}$ Autos caratulados: »Ríos Sara elena c/ i.s.s.n. s/ acción de amparo” (expte. n 164 - año 2008) 
El haber de los beneficios será móvil. En el caso de incrementos en las remuneraciones sujetas a aportes jubilatorios del personal en actividad, la movilidad se efectuará dentro de los sesenta (60) días de producidos; (...) A partir de la presente y para la aplicación de lo precedentemente establecido, las prestaciones otorgadas con anterioridad se considerarán como haber inicial jubilatorio a los efectos de las posteriores movilidades.

Actualmente en el ámbito local se presentan dos situaciones respecto de la movilidad de los beneficios jubilatorios, aquellos que obtuvieron su beneficio durante la vigencia de las Leyes 3295/76 y 4917/95, o leyes especiales, y los que se jubilaron durante la vigencia de la Ley 4917 modificada por los Decretos Leyes 22/00 y 167/01.

Respecto de los primeros la situación no requiere mayor análisis, debiéndose aplicar lo dispuesto en la ley vigente al momento del otorgamiento del beneficio, por cuanto que de otra manera se estaría vulnerado un derecho adquirido expresamente reconocido por nuestra Constitución Nacional.

La jurisprudencia de la Corte Suprema es conteste respecto de este tema, conforme lo tiene resuelto en los autos «Gemelli, Esther N. v. Administración Nacional de la Seguridad Social «; «Siri, Ricardo v. Administración Nacional de la Seguridad Social». Más recientemente, en autos «Arrúes, Abraham D. v. Administración Nacional de la Seguridad Social», donde reiteró, “que tratándose de un beneficiario de un régimen previsional que contemplaba la movilidad del $82 \%$ del cargo en el que el solicitante se había desempeñado, corresponde actualizar su haber conforme dicha pauta”.

Ahora bien, respecto de los obtuvieron su beneficio jubilatorio con posterioridad a la vigencia de la Ley 4917/95 modificada por los Decretos-Ley 22/00 y 167/01, la situación se presenta más compleja, por cuanto que el art. 67 no dice nada al respecto. A tal fin se hace necesario recurrir a lo expresado por la Jurisprudencia respecto de este tema:

En lo relativo al régimen de movilidad, la jurisprudencia de la Corte Suprema entendió que debía existir una relación proporcional entre haber jubilatorio y el salario de actividad, en razón de la naturaleza sustitutiva que debe tener el mismo.

Ya vimos con anterioridad que implica relación de proporcionalidad, no obstante, me parece pertinente traer a colación lo expresado por la Cámara 
Federal de la Seguridad Social, que tuvo oportunidad de pronunciarse al respecto, por intermedio de la sala III, el 16/8/1989 en el caso «Bastero, Benjamín v. Caja del Estado», que, cuando

se encuentre afectado el principio de proporcionalidad que debe existir entre haberes de actividad y pasividad, debe ser declarada la inconstitucionalidad de los mismos (...), lo cual se produce cuando «de su aplicación se derive una reducción que supere el $15 \%$ en los haberes percibidos o a percibir por el beneficiario, respecto de los que le hubieren correspondido.

Criterio que ha sido ratificado con posterioridad por la Corte Suprema.

Cabe puntualizar entonces que, tanto la Corte Suprema, como la Cámara Federal de la Seguridad Social, entienden que la determinación del haber y su correspondiente movilidad sobre la base del 67\%, garantiza la debida proporcionalidad que debe existir entre los haberes del personal en actividad y el de pasividad, no perdiendo por ende su carácter sustitutivo. Sin que pueda considerarse como confiscatoria tal reducción.

Consideramos que una futura reforma en la Ley vigente debe implementar un sistema de movilidad automática que garantice que todo el universo de beneficiarios (Jubilados y Pensionados) tengan los aumentos en tiempo y forma. Ahora bien, la determinación del haber y de la movilidad, sobre la base de la debida proporcionalidad entre los haberes de actividad y pasividad, a los fines de que el haber no pierda su poder adquisitivo producto del paso del tiempo y de la inflación, debe hacerse teniendo en cuenta los recursos con los que cuenta cada institución, a los fines de no disponer medidas que pongan en riesgo la sustentabilidad de los sistemas previsionales provinciales. Si los legisladores estimaran la conveniencia de establecer un porcentaje fijo de movilidad en texto de la ley nos parece un criterio razonable, la pauta fijada por la Corte Suprema, mencionada en párrafo anterior, es decir una movilidad entre el $70 \%$ y el $80 \%$.

Hay que tener siempre presente que si se registrara una situación de significativo déficit financiero en la institución, como ocurre actualmente con las cajas de Córdoba y provincia de Buenos Aires, se le brindaría al Gobierno Nacional el argumento que necesita para concretar su intención de que todas las Cajas pasen definitivamente bajo la órbita del ANSeS, situación que iría en desmedro de los jubilados y pensionados de las distintas cajas Provinciales no transferidas. Si aspiramos a un Sistema Federal de Previsión Social que res- 
pete la autonomía de las jurisdicciones provinciales, los sistemas previsionales deben quedar dentro de la órbita de cada provincia.

\section{Financiamiento}

El origen del Patrimonio y los Recursos del Instituto de Previsión Social de la provincia de Corrientes fue establecido por el art. $11^{\circ}$ de la Ley 4917, siguiendo el siguiente esquema de financiamiento:

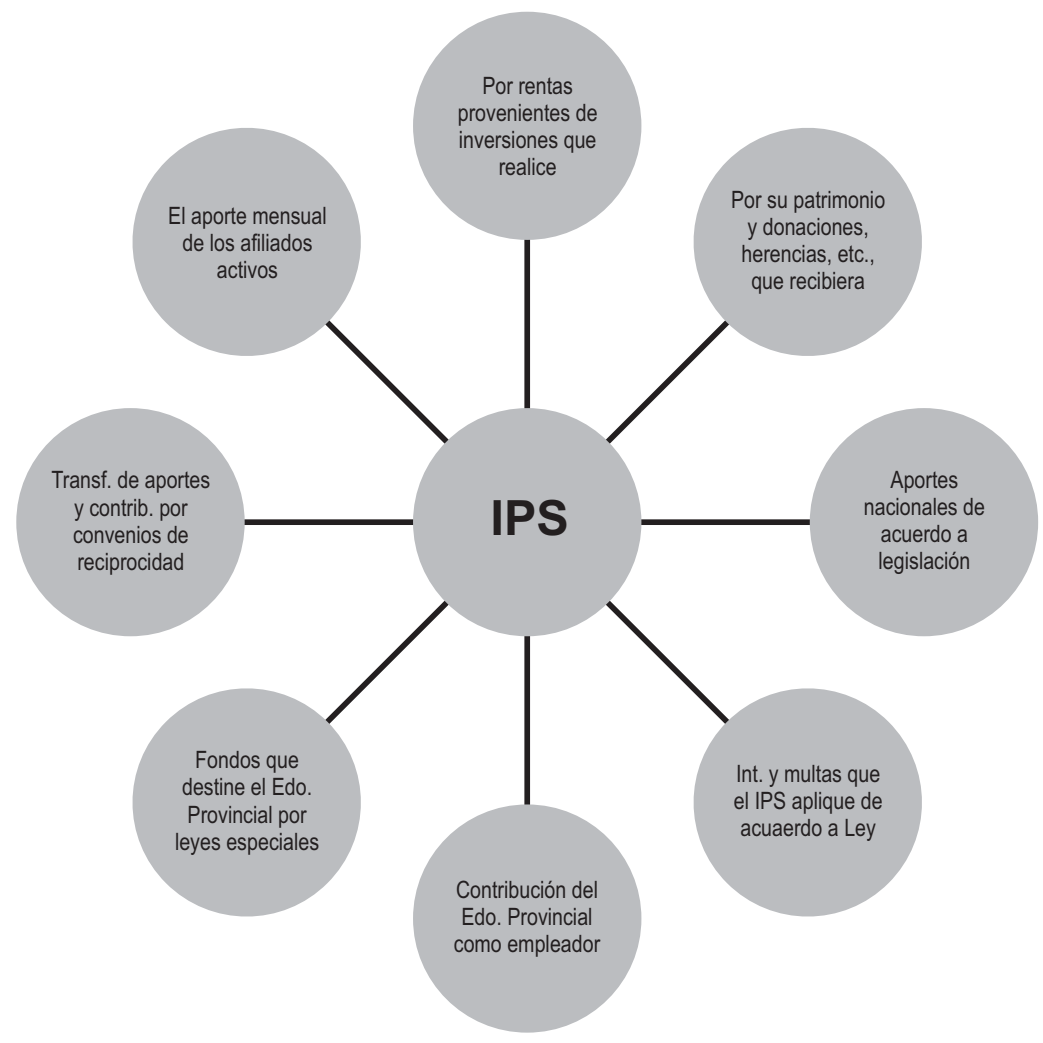

En los últimos años el Instituto se financia con recursos por aportes y contribuciones los que representan un $93 \%$ y solo un $7 \%$ aproximadamente por leyes especiales. 
En lo que respecta a esta cuestión, teniendo en cuenta la situación actual del sistema Previsional de la provincia y que se irá agravando con el tiempo, una reforma al régimen vigente debe contemplar necesariamente un sistema de Reparto Asistido, que permita contar con un mecanismo de financiamiento externo, cuando los aportes y las contribuciones resulten insuficiente para atender a las necesidades del sector. Asimismo, se debería prever la creación de un Fondo Anticíclico en caso de ocurrir algunas contingencias "imprevisibles" (Emergencias Económicas, etc.). Máxime, si tenemos en cuenta que siempre en épocas de crisis económicas la primera variable de ajustes ha sido los salarios de la clase pasiva (jubilados y pensionados).

\section{Beneficiarios: jubilados y pensionados}

Están comprendidas en el régimen todas las personas que presten servicios en cualquiera de los Poderes del Estado Provincial, sus reparticiones descentralizadas e instituciones del régimen municipal, salvo aquellas personas que por disposición legal se hallen incorporadas a otro régimen de previsión o caja provinciales.

A fines del año 2002 el Instituto de Previsión Social de la Provincia de Corrientes contaba con 19.567 beneficiarios, de los cuales el 71,61\% correspondía a jubilaciones y el 28,39\% a pensiones; a fines del año 2005 pasó a contar con 21.386 beneficiarios cifra de la cual el $71,93 \%$ eran jubilaciones y el 28,07\% pensiones.

A fines del año 2012 la cantidad de beneficiarios fue de 24.112, de los cuales el 28,27\% correspondía a pensiones y el $71.73 \%$ a jubilaciones. En cuanto a cantidad de beneficiarios, el aumento fue del 21,71\% en 10 años.

Si se proyecta este crecimiento teniendo en consideración la evolución de los beneficiarios de jubilaciones y pensiones la evolución demográfica de la provincia de Corrientes, evidencia un constante crecimiento en la cantidad de Beneficiarios (jubilados y pensionados), que repercutirá necesariamente sobre la Tasa de sostenimiento del sistema, es decir que cada vez hay más jubilados y menos activos aportantes.

La relación Activos-Pasivos actualmente en la provincia es de 2.87, es decir muy por debajo de lo que se considera optimo (4 o 5 activos aportantes por cada jubilados), situación que indefectiblemente se irá agravando, donde naturalmente la Tasa de Sostenimiento tendera a deteriorarse. 
El Instituto de Previsión Social de la provincia de Corrientes, en la actualidad no sufre de una situación de ahogo financiero, pero si de un equilibrio precario sustentado principalmente sobre una alta tasa de contribución -la más alta del país- 37\% (18,5\% en concepto de aporte y 18,5\% en concepto de contribución). Sin perjuicio de ello, la caja no podrá sustentarse en el tiempo si ocurren cambios en las variables macroeconómicas tanto de la Provincia como en la Nación. Por eso, se hace necesario crear Fondos Anticíclico u otras fuentes de financiamiento en caso de ocurrir algunas contingencias "imprevisibles" (emergencias económicas, etc.).

\section{Otros puntos a tener en cuenta}

1. Déficit en los regímenes específicos que comprenden a los retirados de la policía (Ley 3439) y a los jubilados bancarios (Ley 4588).

2. Alta morosidad en el cobro de las deudas que mantienen con el IPS los organismos oficiales (Dirección Pcial. de Energía). Es necesario e imprescindible custodiar celosamente el estricto cumplimiento de las obligaciones previsionales por parte de todos los entes y organismos que integran el sistema. No realizar regularmente los aportes y contribuciones exigidos por la ley, constituye además de una violación del ordenamiento jurídico con consecuencias punibles, el quebrantamiento de un deber moral ineludible: asegurar al jubilado el merecido derecho a gozar de una vejez tranquila.

3. En contraposición al punto anterior, el cumplimiento en tiempo y forma por parte del IPS;

4. Un contexto demográfico creciente, la composición de los pagos realizados por la Administración Pública a sus empleados, los pagos de las prestaciones por parte del Instituto con déficit financiero creciente, un sistema de reparto puro totalmente colapsado, beneficios con privilegios actualmente insostenibles, etc.,

5. La modificación de la Constitución Provincial, estableció que los recursos municipales son intangibles, por lo tanto no se podrá implementar un sistema automático de retención. Si los municipios dejan de cumplir con sus obligaciones ante el IPS, el cobro de dichas deudas será de difícil recupero; 


\section{Consideraciones finales}

El desempeño de nuestro régimen previsional en la provincia, al igual que la mayoría de las provincias que no transfirieron sus cajas jubilatorias, para los próximos años es realmente preocupante. Esto se desprende de un contexto demográfico creciente, la composición de los pagos realizados por la administración pública a sus empleados y los pagos de las prestaciones por parte del Instituto con déficit financiero creciente, un sistema de reparto totalmente colapsado, beneficios con privilegios insostenibles, regímenes especiales altamente deficitarios (policías, docentes, judiciales), etc.

En tal sentido, se debe avanzar decididamente en la creación de un Sistema Federal de Previsión Social, que se asiente principalmente en el respeto irrestricto de las autonomías de las jurisdicciones provinciales, con la creación de un proyecto de coordinación o articulación entre los distintos regímenes provinciales y nacional que coexisten, es decir, establecer un Sistema que tienda a la debida armonización de las legislaciones previsionales vigentes en las distintas cajas de jubilaciones incluido el Régimen Nacional (ANSeS). Sistema, que debe tender necesariamente hacia una paulatina y sostenida uniformidad en la legislación previsional, de modo que finalmente todos los organismos y cajas del país contengan los mismos beneficios e idénticas exigencias con respecto a edad, antigüedad, años de aportes y determinación y movilidad de los haberes de las prestaciones, sin perjuicio de que la legislación respectiva reconozca y contemple las posibles diferencias que puedan darse al cumplir el mismo tipo de trabajo, pero en diferentes ámbitos y condiciones por el lugar de su prestación.

Este sistema Federal de Previsión Social debe necesariamente ser sobre la base del principio de la Prorrata Tempore, donde cada régimen pague la prorrata del beneficio que a él compete, a los fines de solucionar definitivamente los enormes problemas que genera actualmente el sistema de reciprocidad (caja otorgante, pago de beneficios, transferencias de aportes y contribuciones, etc.).

En lo que respecta a las cajas previsionales (provinciales y municipales), deben tender hacia un sistema de reparto asistido, similar al del sistema nacional, que permita darle previsibilidad y sustentabilidad en el tiempo, teniendo en cuenta, que los recursos genuinos del sistema (aportes y contribuciones) cada vez resultan más insuficientes.

Asimismo, sería conveniente establecer mecanismos tendientes a solucionar los principales problemas que generan el déficit del sistema previsional en nuestra provincia a través de: a) La creación de fondos de afectación específi- 
ca para financiar el déficit de los regímenes especiales -policías, docentes, bancarios, etc.-, o de privilegios -legisladores-, a los fines de que estos déficit no repercutan negativamente sobre el sistema general; b) la creación de un fondo anticíclico en caso de ocurrir algunas contingencias "imprevisibles" (emergencias económicas, etc.).

Y para concluir, entender que la previsión social debe ser vista, analizada y ejecutada como política de Estado. Así lo han entendido los constituyentes que lo ubicaron dentro del art. 14 bis de nuestra Constitución Nacional como un derecho fundamental e imprescriptible de todo ciudadano. Desde dicha óptica, cada organismo de aplicación en materia previsional debe tener normativas y procedimientos claros y precisos, a los fines de contar con un sistema previsional equitativo y sustentable, que tienda principalmente a proteger el derecho a una vejez digna, luego de haber completado los años de vida laboral activa. 